\title{
DESEMPENHO DE CULTIVARES DE ALFACE SOB CULTIVO PROTEGIDO ( $\left.{ }^{\mathbf{1}}\right)$
}

\author{
PAULO ESPÍNDOLA TRANI $\left(2^{*}\right)$; MARIA DO CARMO DE SALVO SOARES NOVO $\left(^{3}\right)$; \\ MÁRIO LUIZ CAVALLARO JÚNIOR $\left({ }^{4}\right)$; CHARLESTON GONÇALVES $\left({ }^{4}\right)$; \\ MARCOS AURÉLIO MAGGIO $\left({ }^{4}\right)$; ANDRESSA BARBOSA GIUSTO $\left({ }^{4}\right)$; MARCELA LEITE VAILATI $\left({ }^{5}\right)$
}

\begin{abstract}
RESUMO
O desempenho de três cultivares de alface (Lactuca sativa L.), sob cultivo protegido, foi avaliado de julho a outubro de 2004, no Instituto Agronômico, em Campinas (SP). O delineamento experimental foi o inteiramente ao acaso, com quatro repetições, sendo avaliadas as cultivares Bariri (tipo alongada), Mariane (tipo crespa) e Verdinha (tipo lisa). Avaliou-se aos 7, 14, 21 e 28 dias, a altura média das plantas e o número de folhas. Também aos 28 dias foram avaliadas a área foliar, o diâmetro, a biomassa fresca e a biomassa seca da cabeça. Houve aumento linear na altura média e no número de folhas das plantas em função do tempo. Aos 28 dias observou-se que a cultivar Bariri, sem diferir da Mariane foi superior à Verdinha quanto à altura média das plantas.Verificou-se ainda que a cultivar Bariri foi superior às outras duas para número de folhas e área foliar; na 'Verdinha' observou-se maior diâmetro de cabeça e maior biomassa fresca de cabeça sem diferir de 'Mariane' para essa última característica.
\end{abstract}

Palavras-chave: estufa agrícola, Lactuca sativa L., produção, desenvolvimento.

\section{ABSTRACT \\ PERFORMANCE OF THREE LETTUCE CULTIVARS IN PLASTIC-GREENHOUSE}

Performance of three lettuce (Lactuca sativa L.) cultivars in plastic-greenhouse was carried out in Campinas, São Paulo State, Brazil, from July to October 2004. The experiment was set up in completely randomized design with four replicates. Bariri (lengthy leaf lettuce), Mariane (crisp head lettuce) and Verdinha (leafy lettuce) cultivars were evaluated for yield, average plant height and number of leaves at 7, 14, 21 and 28 days after transplantation. Head diameter, foliar area and shoot fresh weight were also obtained at 28 days. The effect of sampling period showed linear response in function of time for average plant height and number of leaves. Number of leaves and foliar area were greater in 'Bariri' but 'Verdinha' showed greater head diameter. 'Bariri', without differing from Mariane, showed greater average plant height than 'Verdinha' at 28 days after transplantation. 'Verdinha' showed greater head diameter and head fresh weight, without differing from 'Mariane' as to this character.

Key words: Plastic- protection, Lactuca sativa L., yield, development.

$\left({ }^{1}\right)$ Recebido para publicação em 9 de agosto de 2005 e aceito em 23 de maio de 2006.

$\left({ }^{2}\right)$ Centro de Horticultura, IAC, Caixa Postal 28, 13020-902 Campinas (SP). E-mail: petrani@iac.sp.gov.br. *Autor correspondente.

$\left({ }^{3}\right)$ Centro de Ecofisiologia e Biofísica, IAC, Campinas, SP Caixa Postal 28, 13020-902 Campinas (SP). E-mail: mcdsalvo@hotmail.com.

$\left({ }^{4}\right)$ Pós-graduando da área de Tecnologia da Produção Agrícola, IAC.

$\left({ }^{5}\right)$ Graduanda da Pontifícia Universidade Católica de Campinas. 


\section{Introdução}

A alface é a principal hortaliça folhosa comercializada e consumida pela população brasileira pela facilidade de aquisição e por ser produzida durante o ano inteiro (Oliveira et al., 2004). Essa cultura é muito sensível às condições climáticas principalmente chuva e temperatura (RODRIGUEs et al., 1997). Tradicionalmente, a alface é melhor adaptada a temperaturas mais amenas, com maior produção nas épocas mais frias do ano, em condições de campo (Oliveira et al., 2004), com variação de rendimento em função de cultivares e da mudança climática ocorrida durante o ano (DuARTE et al., 1992).

O cultivo da alface sob estufa agrícola, além de permitir a utilização intensiva da terra e do capital, permite sua produção de maneira controlada, dependendo menos das condições climáticas, e melhor aproveitamento dos insumos; possibilita a distribuição da produção ao longo do ano; regulariza a oferta e proporciona ao produtor a possibilidade de evitar épocas de menor preço (RodRIGUEs et al., 1997).

Segundo NAGAi (1993), até 1993, a preferência predominante no Brasil era para alface de folhas lisas do tipo manteiga, entretanto, tem-se observado, atualmente, grande demanda para o tipo crespa (Oliveira et al., 2004), sendo a participação de folhas crespas atende a $70 \%$ do mercado consumidor dessa folhosa.

Nos últimos anos, tem-se observado no mercado de sementes de alface número crescente de cultivares, sendo algumas delas adaptadas ao cultivo protegido. Para outras, há ausência de informações. A avaliação do desempenho de cultivares, para condições de cultivo protegido, é de grande importância, especialmente quando o cultivo ocorre em época do ano desfavorável. Além disso, RADIN et al. (2004) verificaram que em três cultivares de alface cultivada em estufa, um número final de folhas maior do que as cultivadas em campo, resultando inclusive em uma antecipação da colheita.

No banco de germoplasma do IAC, existem duas cultivares denominadas Bariri (provenientes do município paulista de mesmo nome) e Verdinha (origem indeterminada), as quais vêm se destacando, quanto ao potencial para o comércio. A cultivar Mariane, da Empresa Horticeres, é uma das mais cultivadas na região de Campinas em períodos de temperatura amena. Tais cultivares mostram bom desempenho quanto à produtividade e qualidade quando cultivadas a céu aberto, no campo, porém não se conhece seu potencial para cultivo sob estufa plástica.
O presente trabalho teve como objetivo avaliar o desempenho das cultivares Bariri (tipo alongada), Mariane (tipo crespa) e Verdinha (folhas lisas), quanto ao desenvolvimento e à produção de cabeças, sob cultivo protegido, para as condições edafoclimáticas do Planalto Paulista.

\section{Material e Métodos}

O experimento foi instalado no Núcleo Experimental de Campinas, pertencente ao Instituto Agronômico, em Campinas (SP), em estufa com cobertura plástica de polietileno transparente, tratado para reter raios ultravioletas, com espessura de 150 $\mathrm{m}$, e com laterais cobertas com tela Sombrite de $2 \mathrm{~mm}$ de abertura, desde a superfície do solo até $2 \mathrm{~m}$ de altura. O solo foi classificado como Latossolo Vermelho-Escuro Distroférrico. Os resultados das análises químicas das amostras de solo coletadas na área do experimento foram: M.O. $=28 \mathrm{~g} \mathrm{dm}^{-3} ; \mathrm{pH}$ $\left(\mathrm{CaCl}_{2}\right)=6,0 ; \mathrm{P}($ resina $)=31 \mathrm{mmol}_{\mathrm{c}} \mathrm{dm}^{-3} ; \mathrm{K}=5,3$ $\mathrm{mmol}_{\mathrm{C}} \mathrm{dm}^{-3} ; \mathrm{Ca}=26 \mathrm{mmol}_{\mathrm{C}} \mathrm{dm}^{-3} ; \mathrm{H}+\mathrm{Al}=25 \mathrm{mmol}_{\mathrm{C}} \mathrm{dm}^{-}$ 3. $\mathrm{CTC}=64 \mathrm{mmol}_{\mathrm{C}} \mathrm{dm}^{-3} ; \mathrm{V}=61 \% ; \mathrm{S}=9 \mathrm{mgdm}^{-3} ; \mathrm{Na}=3$ $\mathrm{mgdm}^{-3} ; \mathrm{Fe}=97 \mathrm{mgdm}^{-3} ; \mathrm{Mn}=80 \mathrm{mgdm}^{-3} ; \mathrm{Cu}=6$ $\mathrm{mgdm}^{-3}$; Zn: $5 \mathrm{mgdm}^{-3}$ e B $=0,3 \mathrm{mgdm}^{-3}$. As mudas de alface foram produzidas em bandejas de poliestireno com 128 células, preenchidas com Plantmax HA, sendo semeadas em 23/7/2004, duas sementes por cavidade. O desbaste foi realizado cinco dias após a emergência das plântulas, sendo mantida uma planta por célula até o transplante realizado aos 30 dias. As mudas foram transplantadas no espaçamento de 0,25 por $0,25 \mathrm{~m}$, quando estavam com altura média entre 5 e 7 centímetros, sendo as entrelinhas cobertas com grama-batatais (Paspalum notatum Flugge), seca e triturada.

O experimento foi disposto no delineamento inteiramente ao acaso, com três tratamentos (Bariri, Mariane e Verdinha) e quatro repetições, com parcelas subdivididas para a época de avaliação. A calagem, adubação e tratamentos fitossanitários foram realizados conforme recomendado por NAGAI (1998). As parcelas eram constituídas de canteiros com cinco 1-inhas de $1 \mathrm{~m}$ de comprimento espaçadas entre si por $0,25 \mathrm{~m}$, correspondendo a 20 plantas. As avaliações foram realizadas aos $7,14,21$ e 28 dias após o transplantio, sendo avaliadas a altura média das plantas e o número de folhas em cinco plantas de cada parcela, escolhidas aleatoriamente. Na colheita, aos 28 dias após o transplantio, foram avaliados também o diâmetro das cabeças, a área foliar e a biomassa fresca e a seca da cabeça. 
Para número de folhas e altura média das plantas, a análise de variância foi realizada de acordo com o método para parcelas subdivididas (STEEL e TORREY, 1980), empregando-se o teste de Tukey ( $5 \%$ ) para comparação das médias entre cultivares e a regressão polinomial para os efeitos de época de avaliação. Os dados de número de folhas foram transformados em raiz quadrada de $\mathrm{x}$ para análise estatística. Para as variáveis área foliar, diâmetro da cabeça, biomassa fresca e seca das plantas foi realizada a análise de variância empregando-se o teste F e quando significativo, comparou-se as cultivares pelo teste de Tukey a $5 \%$.

\section{Resultados e Discussão}

Em referência ao efeito de época de avaliação para cada cultivar, verificou-se que a altura média das plantas e o número de folhas aumentaram linearmente em função do tempo (Figura 1) sugerindo a possibilidade de se esperar mais alguns dias para colher o material. Em relação à altura média das plantas, verificou-se para todas as cultivares alturas de 17,0 a $18,3 \mathrm{~cm}$, por ocasião da colheita ( 28 dias após transplante das mudas) (Figura 1A).

A comparação entre as três cultivares, por ocasião da colheita, para altura média das plantas, número de folhas, área foliar e diâmetro da cabeça é apresentada na Figura 2. De modo geral, observou-se em 'Bariri' maior altura média que 'Verdinha', maior número de folhas e área foliar que 'Verdinha' e 'Mariane' (Figuras 2A, 2B e 2C).
Embora a cultivar Mariane tenha um talo mais cheio próximo da base, esperava-se que sua área foliar (Figura 2C) fosse inferior à das outras cultivares, pois suas folhas são mais recortadas . Entretanto, essa não diferiu da 'Verdinha' com folhas inteiras e lisas. Com o aumento do consumo de alface minimamente processada (lavada e picada), torna-se interessante a colheita de plantas de maior porte, principalmente com maior área foliar, cujo maior volume da cabeça de alface picado pode representar maior lucro ao produtor dessa hortaliça. Segundo Oliveira et al. (2004), na produção de alface, o número de folhas é uma característica importante e está intimamente associado à temperatura do ambiente de cultivo e ao fotoperíodo. RADIN et al. (2004) observaram diferenças no número de folhas entre as cultivares Regina, Verônica e Marisa, tanto em estufa agrícola, como quando cultivada no campo.

Na alface 'Verdinha' observou-se maior diâmetro de cabeça comparado ao das outras cultivares (Figura 2D). Embora a alface 'Bariri' tenha maior número de folhas, não é característica dessa cultivar formar cabeça como, comumente ocorre nas outras cultivares lisas (BezerRa Neto et al., 2003), razão pela qual seu diâmetro de cabeça foi menor. Em 'Verdinha' ocorreu maior biomassa fresca de cabeça do que 'Bariri' (Figura 3A). Não houve diferença entre cultivares quanto à biomassa seca (Figura 3B). De maneira geral, as três cultivares de alface avaliadas neste estudo tiveram bom desempenho sob cultivo protegido, podendo ser comercializadas in natura e possivelmente na forma minimamente processada.
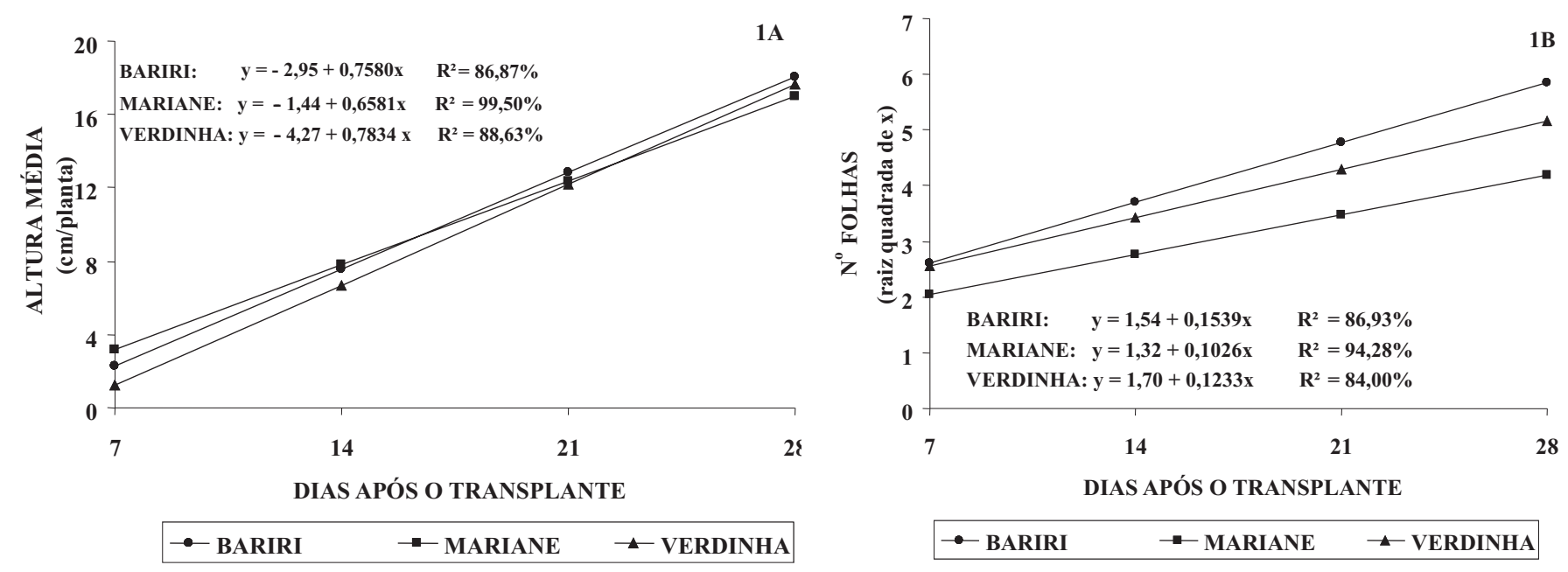

Figura 1. Efeito das épocas de avaliação nas cultivares Bariri, Mariane e Verdinha para altura média das plantas (1A) e número de folhas (1B) . Campinas (SP), 2004. 

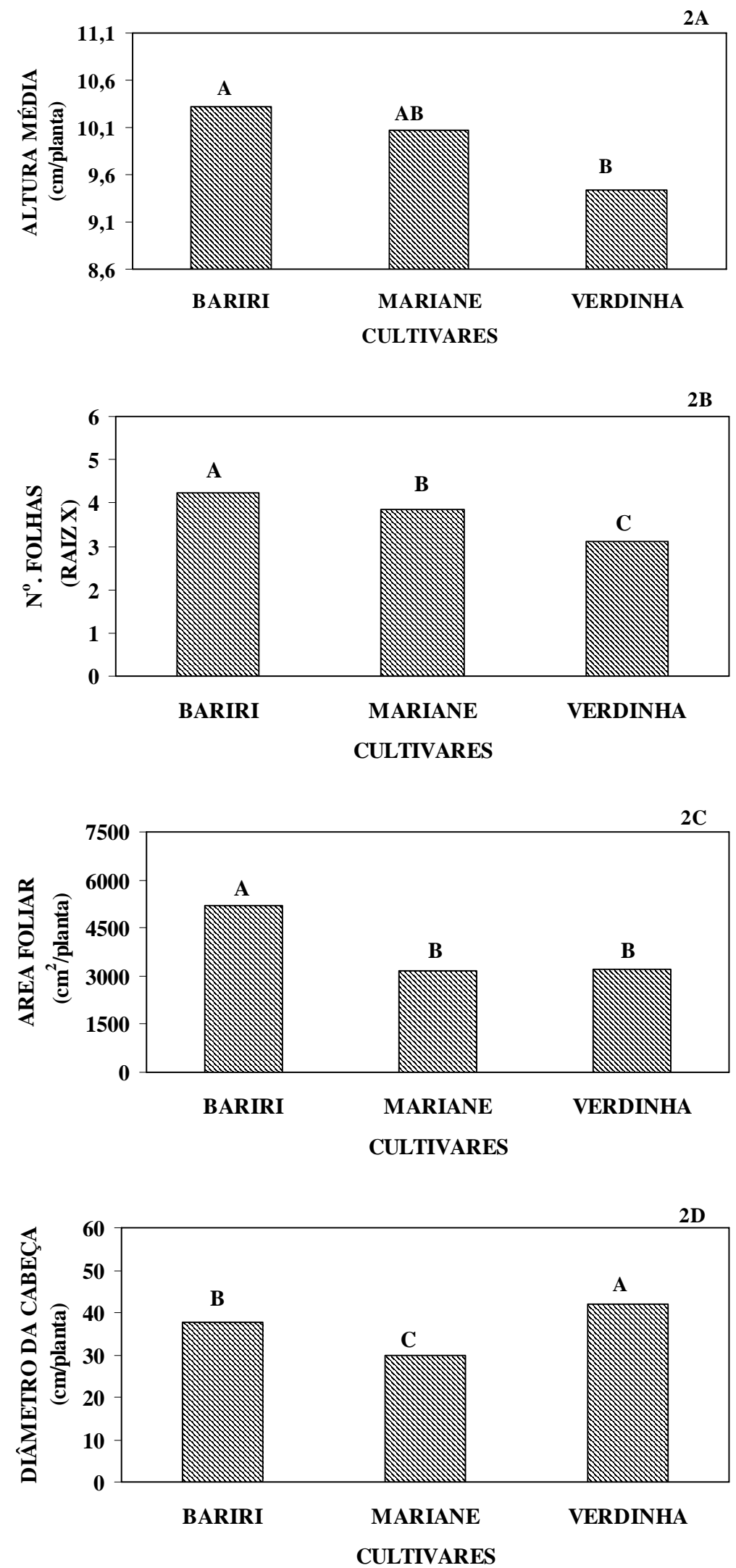

Figura 2. Comparação entre as cultivares Bariri, Mariane e Verdinha para altura média de plantas (2A), número de folhas (2B), área foliar (2C) e diâmetro de cabeça (2D), por ocasião da colheita ( Tukey a 5\%). Campinas (SP), 2004. 

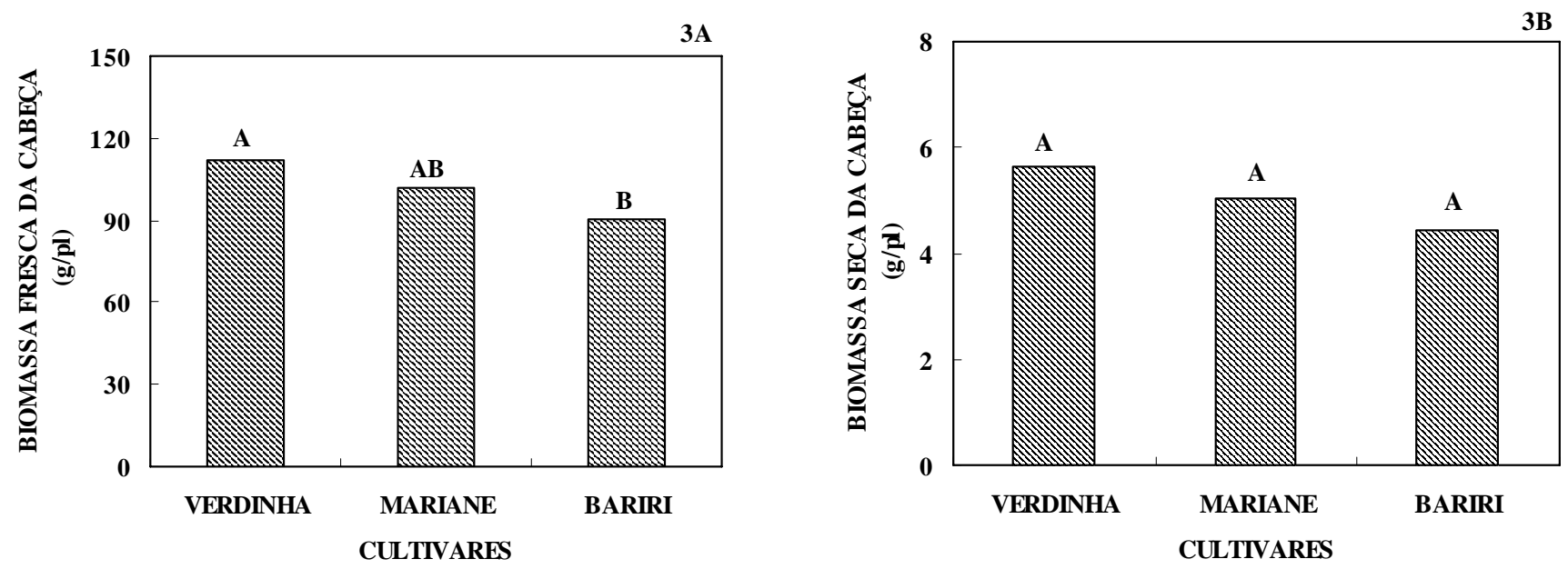

Figura 3. Comparação entre as cultivares Verdinha, Mariane e Bariri quanto à biomassa fresca e a seca de cabeça, por ocasião da colheita (Tukey a 5\%). Campinas (SP), 2004.

\section{Conclusão}

As três cultivares tiveram bom desempenho sob cultivo protegido, sendo 'Bariri' a cultivar mais produtiva e juntamente com a alface 'Verdinha' constituem-se em cultivares com bom potencial para o comércio.

\section{Agradecimentos}

Os autores agradecem ao Sr. Lourival Francisco da Silva e Osvaldo Roberto Euchenberger, funcionários do Centro de Horticultura do IAC, pelo apoio na realização do trabalho.

\section{Referências}

BEZERRA, NETO, F.; ANDRADE, F.V.; NEGREIROS, M.Z.; SANTOS JÚNIOR, J.J. Desempenho agroeconômico do consórcio cenoura $x$ alface lisa em dois sistemas de cultivo em faixa, Horticultura Brasileira, Brasília, v.21, n.4, p.635-641, 2003.

DUARTE, R.L.R.; SILVA, P.H.S.; RIBEIRO, V.Q. Avaliação de cultivares de alface nos períodos chuvosos e secos em Teresina - PI. Horticultura Brasileira, Brasília, v.10, n.2, p.106-108, 1992.

NAGAI, H. Alface (Lactuca sativa L.). In: FAHL, J.I.;CAMARGO, M.B.P.; PIZZINATTTO, M.A.; BETTI, J.A.; DE MARIA, I.C.; FURLANI, A.M.C. (Ed.). Instruções agrícolas para as principais culturas econômicas. $6^{\text {a }}$. ed. rev. atual. Campinas: Instituto Agronômico, 1998. p.173-174.

NAGAI, H. Alface tipo manteiga. In: FURLANI, A.M.C. ; VIÉGAS, G.P. (Eds.). O melhoramento de plantas no Instituto Agronômico. Campinas: Instituto Agronômico, 1993. p.204-221.
OLIVEIRA, A.C.B.; SEDIYAMA, M.A.N.; PEDROSA, M.W.; GARCIA, N.C.P.;GARCIA, S.L.R. Divergência genética e descarte de variáveis em alface cultivada sob sistema hidropônico. Acta Scientiarum, Maringá, v.26, n.2, p.211-217, 2004.

RADIN, B.; REISSER JÚNIOR, C.; MATZENAUER, R.; BERGAMASCHI, H. Crescimento de cultivares de alface conduzidas em estufa e a campo. Horticultura Brasileira, Brasília, v.22, n.2, p.178-181, 2004.

RODRIGUES, A.B.; MARTINS, M.I.E.G.; ARAÚJO, J.C.C. Avaliação econômica da produção de alface em estufa. Informações Econômicas, São Paulo, v.27, n.1, p.27-33, 1997.

STEEL, R.G.D.; TORREI, J.H. Analysis of variance. IV: Splitplot designs and analysis. In: STEEL, R.G.D.; TORREI, J.H. (Ed.). Principles and procedures of statistics. $2 \mathrm{ed}$. New York: Mc Graw Hill, 1980. Chapter 16. p.377-400. 